\title{
Analysis of Sulfonated Anthraquinone Dyes by Electrospray Ionization Quadrupole Time-of-flight Tandem Mass Spectrometry
}

Min Li, Yufei Chen, David Hinks and Nelson R Vinueza*

Department of Textile Engineering, Chemistry and Science, North Carolina State University, Raleigh, NC 27695, USA

\begin{abstract}
A tandem mass spectrometric method using a commercial quadrupole-time-of-flight (QTOF) mass spectrometer is described for the identification of sulfonated anthraquinone type dyes, having a 1-amino anthraquinone-2sulfonate backbone. A total of 9 anthraquinone dye model compounds were evaporated and ionized via negative-ion electrospray ionization (ESI). Ionization of the sulfonated anthraquinone compounds primarily results in the formation of deprotonated molecules, [M-H]-. Once ionized, the ions were subjected to collision-activated dissociation (CAD). The type of neutral molecules or ions cleaved during CAD facilitates identification of the original compound. In most cases, a loss of 64 amu was observed for all dyes and was confirmed to be $\mathrm{SO}_{2}$ by high resolution mass spectrometry analysis. A unimolecular rearrangement of the sulfonate $\left(\mathrm{SO}_{3}\right)$ group was triggered by $\mathrm{CAD}$ that allowed loss of $\mathrm{SO}_{2}$. Also, it was found that different group functionalities attached to the anthraquinone backbone (e.g., secondary aromatic amines and secondary alkyl amines) have specific fragmentation pathways that can be used to distinguish them under similar CAD conditions. For example, an anthraquinone having a secondary amine with an aromatic group attached to it (e.g., Acid Blue 25) can be differentiated from an anthraquinone having a secondary alkyl amine (e.g., Acid Blue 62) based on the product ions. The resultant fragmentation patterns could contribute to the identification of unknown dyes with similar chemical structures. The method was also successfully used in concert with targeted CAD for quantification purposes. The methodology presented here is the first stage in building a high resolution mass spectrometry dye database from the extensive uncatalogued Max Weaver Dye Library at North Carolina State University.
\end{abstract}

Keywords: Acid dyes; Anthraquinone; Mass spectrometry; Tandem mass spectrometry; Structural elucidation

\section{Introduction}

The ability to identify unknown dyes in complex mixtures is of great importance in the areas of food, environment, human health, and forensics [1-5]. For example, acid dye manufacturing constitutes one of the highest production worldwide, and is normally used on nylon, synthetic polyamides, wool, silk, paper, inks and leather [6]. The continuous development of new products requiring improved dyeing properties (i.e., leveling characteristics, washfastness, and lightfastness) requires the use of suitable analytical tools for structural identification of new dyes, their byproducts and degradation products, as well as synthetic impurities. However, the chemical structures of dyes are often protected by patents, making their characterization a challenge. In addition, the same dye type may have a different structure depending on the colorant manufacturer. For this reason, we set about to develop a suitable methodology for the analysis of these compounds, both qualitatively and quantitatively.

Mass spectrometry (MS) has evolved into an essential and powerful tool for mixture analysis $[7,8]$. The high sensitivity, specificity, and speed of MS provides rapid and useful molecular-level information regarding complex mixtures. The development of atmospheric pressure ionization techniques-such as electrospray ionization (ESI)-smoothed the coupling of high-performance liquid chromatography (HPLC)an invaluable tool in mixture analysis-with MS $[9,10]$. This approach allows for the determination of the molecular weights and elemental composition of known and unknown analytes. In order to obtain detailed information on the molecular structures of these analytes, tandem mass spectrometry (MS/MS) is required [11-17]. MS/MS elucidates the structures of ionized compounds by their fragmentation reactions through collision-activated dissociation (CAD) [18-20].

The analysis of anionic dyes, such as sulfonated and sulfated dyes, by MS has commonly used negative-ion ESI as an ionization source due to the polar character of the dyes [21-23]. The use of this ionization technique produces a series of deprotonated molecules, which can be very useful in the determination of the molecular weight (MW) of the dye [21]. The total number of acid groups can also be determined with negative-ion ESI based on the number of protons replaceable by sodium ions [24].

We report here the use of ESI in combination with a quadrupoletime-of-flight (QTOF) MS/MS as a way to determine specific fragmentation pathways of commercial sulfonated anthraquinone dyes for identification purposes. In this study, a series of sulfonated acid dyes containing the structure of 1-amino anthraquinone-2-sulfonate (Figure 1) were analyzed by HPLC coupled to ESI-MS and ESI-MS/MS with the purpose to investigate the featured fragment loss of sulfonated anthraquinone dyes, as well as the fragmentation mechanism by which these molecules disassociate. This will be part of the first phase of building a high resolution mass spectrometry dye database from the extensive uncatalogued Max Weaver Dye Library donated from Eastman Chemicals, with approximately 100,000 dyes, to North Carolina State University.

*Corresponding author: Nelson R Vinueza, Department of Textile Engineering Chemistry and Science, North Carolina State University 2401 Research Dr. Box 8301 Raliegh, NC 27695 , USA, Tel: +1-919- 515-6558; Fax (+1)919-515-6532; E-mail: nrvinuez@ncsu.edu

Received November 30, 2015; Accepted January 11, 2016; Published January 20, 2016

Citation: Li M, Chen Y, Hinks D, Vinueza NR (2016) Analysis of Sulfonated Anthraquinone Dyes by Electrospray lonization Quadrupole Time-of-flight Tandem Mass Spectrometry. J Textile Sci Eng 6: 236. doi:10.4172/2165-8064.1000236

Copyright: (c) $2016 \mathrm{Li} \mathrm{M}$, et al. This is an open-access article distributed under the terms of the Creative Commons Attribution License, which permits unrestricted use, distribution, and reproduction in any medium, provided the original author and source are credited. 


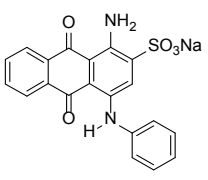

Acid Blue 25

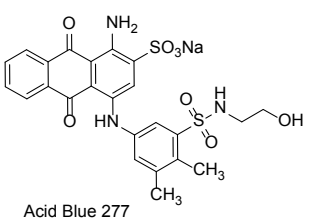

(1)

Sodium anthraquinone-2-sulfonate

Figure 1: Anthraquinone derivatives studied

\begin{tabular}{|l|l|l|l|l|}
\hline No. & Name & Manufacturer & Molecular formula & $\mathbf{M W}^{\mathbf{a}}$ \\
\hline 1 & Acid Blue 25 & M. Dohmen & $\mathrm{C}_{20} \mathrm{H}_{14} \mathrm{~N}_{2} \mathrm{O}_{5} \mathrm{~S} \mathrm{Na}$ & 416.38 \\
\hline 2 & Acid Blue 45 & Ciba Geigy & $\mathrm{C}_{14} \mathrm{H}_{10} \mathrm{~N}_{2} \mathrm{O}_{10} \mathrm{~S}_{2} \mathrm{Na}_{2}$ & 474.33 \\
\hline 3 & Acid Blue 40 & M. Dohmen & $\mathrm{C}_{22} \mathrm{H}_{16} \mathrm{~N}_{3} \mathrm{O}_{6} \mathrm{~S} \mathrm{Na}$ & 473.43 \\
\hline 4 & Acid Blue 62 & Classic Dyestuffs & $\mathrm{C}_{20} \mathrm{H}_{19} \mathrm{~N}_{2} \mathrm{O}_{5} \mathrm{SNa}$ & 422.43 \\
\hline 5 & Acid Blue 129 & Sigma-Aldrich & $\mathrm{C}_{23} \mathrm{H}_{21} \mathrm{~N}_{2} \mathrm{O}_{5} \mathrm{SNa}$ & 460.48 \\
\hline 6 & Acid Blue 277 & Ciba Geigy & $\mathrm{C}_{24} \mathrm{H}_{23} \mathrm{~N}_{3} \mathrm{O}_{8} \mathrm{~S}_{2} \mathrm{Na}$ & 567.57 \\
\hline 7 & $\begin{array}{l}\text { 1-amino anthraquinone-2- } \\
\text { sulfonic acid }\end{array}$ & Sigma-Aldrich & $\mathrm{C}_{14} \mathrm{H}_{9} \mathrm{NO}_{5} \mathrm{~S}$ & 303.29 \\
\hline 9 & $\begin{array}{l}\text { Sodium anthraquinone-2- } \\
\text { sulfonate }\end{array}$ & Sigma-Aldrich & $\mathrm{C}_{14} \mathrm{H}_{7} \mathrm{O}_{5} \mathrm{~S} \mathrm{Na}$ & 310.26 \\
\hline
\end{tabular}

a Molecular Weight (MW)

Table 1: Sulfonated anthraquinone acid dyes and sulfonated anthraquinone mode compounds.

\section{Materials and Methods}

\section{Chemicals}

Methanol and acetonitrile (LC-MS grade) were purchased from Honeywell \& Burdick Jackson (Muskegon, MI, USA). The solvents were filtered through $0.22 \mu \mathrm{m}$ Millipore filters (Whatman, GE Healthcare, UK). Ammonium formate (>99\%, HPLC grade, Fluka, Switzerland), formic acid ( $98 \%$, MS grade), Sodium anthraquinone-2-sulfonate (A1), 1-Amino anthraquinone-2-sulfonic acid (A2) and Acid blue 129 were purchased from Sigma Aldrich (St Louis, MO, USA). The acid dyes (Table 1 and Figure 1) were supplied by Ciba Specialty Chemicals, M. Dohmen, and Classic Dyestuffs.

\section{Sample preparation}

Standard dye solutions were prepared at $1 \mathrm{mg} / \mathrm{mL}$ concentrations in HPLC grade 70:30 (v/v) methanol $(\mathrm{MeOH}) /$ acetonitrile $\left(\mathrm{CH}_{3} \mathrm{CN}\right)$. All solutions for analysis were prepared by adding $20 \mu \mathrm{L}$ of standard dye solution to $980 \mu \mathrm{L}$ of water (Milli-Q).

\section{Instrumentation}

Liquid chromatography/mass spectrometry (LC/MS): The experiments were carried out using an Agilent (Santa Clara, CA)
Accurate Mass 6520 Q-TOF mass spectrometer equipped with an ESI source operating in negative-ion mode ((-)ESI) and coupled with an Aglient 1260 SL HPLC system. The chromatography runs were performed using an Agilent Zorbax Eclipse Plus $\mathrm{C}_{18}$ column $(2.1 \times 50$ $\mathrm{mm}, 3.5 \mu \mathrm{m}$ ) with a Zorbax Eclipse Plus $\mathrm{C}_{18}$ narrow bore guard column $(2.1 \times 12.5 \mu \mathrm{m}, 5 \mu \mathrm{m})$. The mobile phase used for separation consisted of a mixture of $20 \mathrm{mM}$ ammonium formate and $0.01 \%$ formic acid in $\mathrm{H}_{2} \mathrm{O}(\mathrm{A})$ and $70: 30 \mathrm{MeOH} / \mathrm{CH}_{3} \mathrm{CN}(\mathrm{B})$. The flow rate was $0.5 \mathrm{~mL} /$ min with an injection volume of $3 \mu \mathrm{L}$. Negative ESI source parameters were as follows: nebulizer pressure, 35 psi; capillary voltage, $4000 \mathrm{~V}$; drying gas flow, $12 \mathrm{~L} / \mathrm{min}$ at $350^{\circ} \mathrm{C}$; and fragmentor voltage, $110 \mathrm{~V}$. The instrument was operated in $4 \mathrm{GHz}$ high resoltuion mode. Instrument control, data aquisistion, and analysis were performed using Agilent MassHunter Workstation Acquisition and Agilent MassHunter Qualitative Analysis B.06.00.

Collision activated dissociation (CAD): MS/MS experiments were performed on the collision cell (hexapole) of the QTOF by selecting the ion of interest with an isolation width of $1.3 \mathrm{Da}$ (narrow) and colliding the ion with nitrogen gas (99.9995\%) with collision energy of $40 \mathrm{~V}$. All fragment ions were guided to the TOF mass analyser for detection.

Targeted MS/MS QTOF quantitation for acid blue 25: Quantitation of Acid Blue 25 (AB25) was achieved by using the fragment ion (m/z 329.0926) abundance generated from the corresponding deprotonated dye molecule. Five calibration solutions of AB25 were prepared $(20.0,40.0,60.0,80$, and $100.0 \mu \mathrm{g} / \mathrm{mL}$ in $70: 30$ $\mathrm{MeOH} / \mathrm{CH}_{3} \mathrm{CN}$ ) for calibration. A solution containing $50.0 \mu \mathrm{g} / \mathrm{mL}$ was analyzed by this MS/MS method and validated with a traditional liquid chromatographic method. All experiments were run at least three times for reproducibility purposes.

\section{Results}

A total of nine anthraquinone compounds were examined via (-) ESI/MS/MS. Most analytes primarily formed stable deprotonated molecules upon negative-ion ESI when using the 70:30 MeOH/ $\mathrm{CH}_{3} \mathrm{CN}$ as the solvent. The deprotonated molecules were subjected to CAD to obtain structural information. High-resolution measurements were carried out to verify the identities of the neutral molecules lost upon fragmentation. A detailed discussion on each of the anthraquinone derivatives studied is provided below.

\section{Anthraquinones model compounds}

A1, was the simplest anthraquinone derivative studied; it contained a sulfonate group at the 2 position with no other substituents on the aromatic system. Under negative-ion ESI conditions A1 forms an abundant deprotonated molecule $[\mathrm{M}-\mathrm{H}]$, which fragments upon $\mathrm{CAD}$ by loss of $\mathrm{SO}_{2}$-confirmed by exact mass measurements (Table 2) to generate a unique fragment ion with a mass-to-charge ratio $(\mathrm{m} / \mathrm{z})$ of 223.0429. The loss of this neutral $\mathrm{SO}_{2}$ molecule suggested a rearrangement of the sulfonate group $\left(\mathrm{SO}_{3}\right)$, which is in agreement with previous theoretical [25] and experimental [26] studies on aromatic systems. The fragment ion after the $\mathrm{SO}_{3}$ rearrangement is considered a phenoxide anion and is useful for identification of similar structures.

A2, having an amino group at the ortho-positon to the sulfonate group, was found to undergo loss of $\mathrm{SO}_{2}$ upon $\mathrm{CAD}$ of the deprotonated ion, giving a single fragment ion with $\mathrm{m} / \mathrm{z} 238.0512$ (Table 2). This fragment ion also generates a phenoxide anion, which was confirmed by high resolution MS.

In order to understand the fragmentation efficiency of these two 
Citation: Li M, Chen Y, Hinks D, Vinueza NR (2016) Analysis of Sulfonated Anthraquinone Dyes by Electrospray lonization Quadrupole Time-of-flight Tandem Mass Spectrometry. J Textile Sci Eng 6: 236. doi:10.4172/2165-8064.1000236

Page 3 of 5

\begin{tabular}{|c|c|c|}
\hline Analyte (MW) & MS (m/z) & MS/MS CAD fragment ions (m/z) \\
\hline A1 (310.26) & {$[\mathrm{M}-\mathrm{H}]^{-\mathrm{b}}(287.0022)$} & $287.0022-\mathrm{SO}_{2}(223.0409)$ \\
\hline A2 (303.28) & {$[\mathrm{M}-\mathrm{H}]^{-}(302.0129)$} & $302.0129-\mathrm{SO}_{2}(238.0512)$ \\
\hline Acid blue 25 (416.38) & {$[\mathrm{M}-\mathrm{H}]^{-}(393.0529)$} & $\begin{array}{l}\text { 393.0529- } \mathrm{SO}_{2}(\mathbf{3 2 9 . 0 9 2 6 )} \\
393.0529-\mathrm{NHC}_{6} \mathrm{H}_{5}(301.0944) \\
393.0529-\mathrm{SO}_{2}-\mathrm{NHC}_{6} \mathrm{H}_{5}(329.0926)\end{array}$ \\
\hline Acid blue 40 (474.33) & {$[\mathrm{M}-\mathrm{H}]^{-}(450.0763)$} & $\begin{array}{l}\text { 450.0763- } \mathrm{SO}_{2}(\mathbf{3 8 6 . 1 1 5 1}) \\
450.0763-\mathrm{SO}_{2}-\mathrm{C}_{2} \mathrm{H}_{3} \mathrm{O}(386.1151) \\
450.0763-\mathrm{SO}_{2}-\mathrm{C}_{8} \mathrm{H}_{9} \mathrm{~N} \mathrm{O}(237.0429) \\
450.0763-\mathrm{SO}_{2}-\mathrm{C}_{8} \mathrm{H}_{8} \mathrm{NO}(252.0540)\end{array}$ \\
\hline Acid blue 45 (473.43) & {$[\mathrm{M}-\mathrm{H}]^{-}(428.9781)$} & $\begin{array}{l}\text { 428.9781- } \mathrm{SO}_{2}(\mathbf{3 6 5 . 0 0 5 2 )} \\
428.9781-\mathrm{C}_{6} \mathrm{H}_{12} \mathrm{~N}(289.0043) \\
428.9781-\mathrm{SO}_{2}-\mathrm{SO}_{2}(285.0527)\end{array}$ \\
\hline Acid blue 62 (422.43) & {$[\mathrm{M}-\mathrm{H}]^{-}(399.1009)$} & $\begin{array}{l}\text { 399.1009- } \mathrm{C}_{6} \mathrm{H}_{11}(\mathbf{3 1 6 . 0 1 5 5 )} \\
399.1009-\mathrm{SO}_{2}(289.0060) \\
399.1009-\mathrm{SO}_{2}-\mathrm{C}_{6} \mathrm{H}_{11}(252.0533)\end{array}$ \\
\hline Acid Blue 129 (460.48) & {$[\mathrm{M}-\mathrm{H}]^{-}(435.1020)$} & $\begin{array}{l}\text { 435.1020- } \mathrm{SO}_{2}(371.1412) \\
435.1020-\mathrm{SO}_{2}-\mathrm{C}_{6} \mathrm{H}_{11}(252.0548) \\
435.1020-\mathrm{SO}_{2}-\mathrm{C}_{7} \mathrm{H}_{12} \mathrm{~N}(225.0464)\end{array}$ \\
\hline Acid blue 277 (567.57) & {$[\mathrm{M}-\mathrm{H}]^{-}(544.0846)$} & 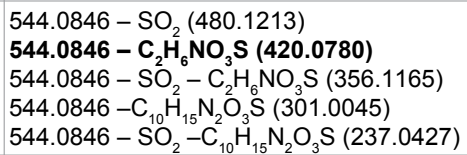 \\
\hline
\end{tabular}

aThe $\mathrm{m} / \mathrm{z}$ value is the monoisotopic mass. ${ }^{b}$ Deprotonated molecule, the sodium $(\mathrm{Na}+$ ) cation under negative-ion $\mathrm{ESI}$ conditions will not be added to the $\mathrm{m} / \mathrm{z}$ value. The $\mathrm{m} / \mathrm{z}$ value of deprotonated molecule will differ by one or two sodium ions and/or one hydrogen atom from the total molecular weight of the dye.

Table 2: lons formed upon ESI as well as the product ions formed upon CAD experiments for sulfonated dyes.

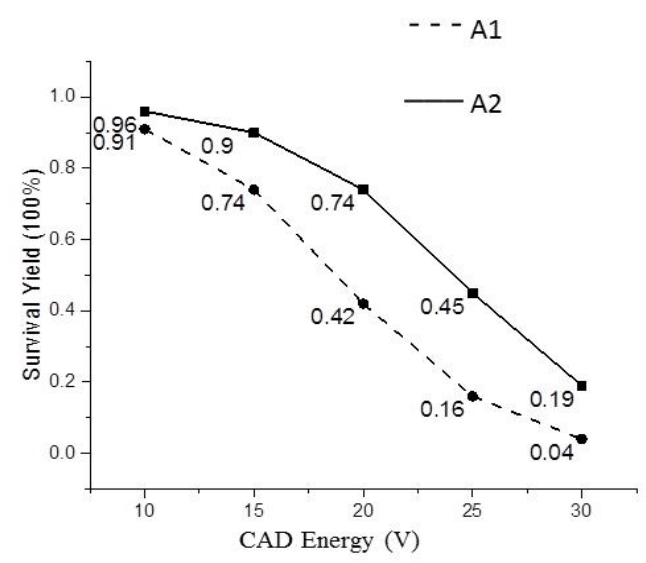

Figure 2: Survival yield diagrams for deprotonated A1 and deprotonated A2.

molecules, the two compounds were fragmented at the same CAD energies (ranging from 10 to $35 \mathrm{~V}$ in $5 \mathrm{~V}$ intervals). The Survival Yield (SY) methodology [27-29] was used as defined in Eqn. 1:

$$
\mathrm{SY}=\frac{\mathrm{I}_{\mathrm{p}}}{\mathrm{I}_{\mathrm{p}}+\sum \mathrm{I}_{\mathrm{f}}}
$$

where $I_{p}$ is the intensity of the precursor ion (deprotonated molecule) and $\sum \mathrm{I}_{\mathrm{f}}^{\mathrm{p}}$ is the sum of fragment intensities. A higher SY suggests the compound requires higher energy to be fragmented. Comparison of the SY between the compounds $\mathbf{A 1}$ and $\mathbf{A 2}$ is shown in Figure 2. The results suggest that the $\mathbf{A} \mathbf{2}$ requires higher energy to fragment.

A possible explanation of the extra energy needed for fragmentation of $\mathbf{A} \mathbf{2}$ can be related to hydrogen bonding between the hydrogen atom of the amino group and the oxygen atom of the sulfonate group. This can form a six-membered ring that stabilizes the deprotonated

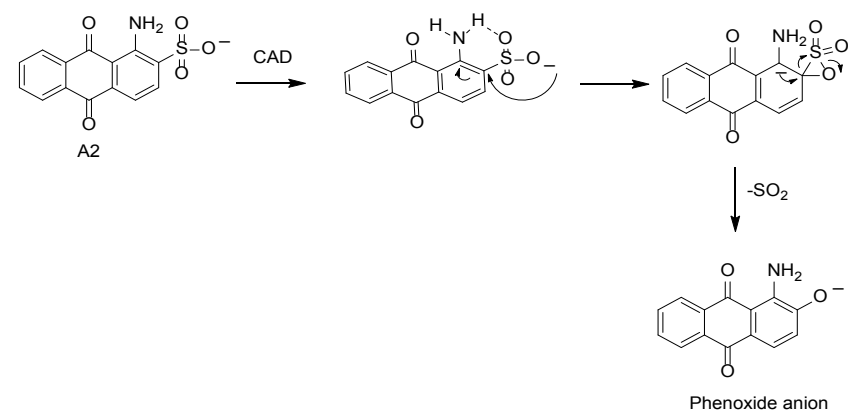

Scheme 1: Proposed mechanism of the loss of $\mathrm{SO}_{2}$ from A2 (Rationalization of $\mathrm{SO}_{3}$ rearragment and the generation of the phenoxide anion).

molecule. A proposed mechanism of the sulfonate rearrangement is depicted in Scheme 1. The formation of an epoxide that leads to the cleavage of the $\mathrm{SO}_{2}$ molecule has been proven as a favorable pathway by theoretical studies [25].

Acid dyes containing a secondary aromatic amine: Acid blue dyes 25, 40, 129 and 277 form abundant deprotonated molecules [M$\mathrm{H}]^{-}$upon ionization via negative-ion ESI. All deprotonated acid dyes fragment upon CAD with a main fragment ion loss of $\mathrm{SO}_{2}$ and a minor fragment ion loss of the secondary aromatic amine $\left(\mathrm{NHC}_{6} \mathrm{H}_{5}\right.$, Table 2$)$. These results suggest that the lowest energy pathway of fragmentation is the rearrangement of the sulfonate group to lose $\mathrm{SO}_{2}$ as compared to the loss of the secondary aromatic amine. This characteristic fragmentation pathway is useful in determining possible substituents present on the anthraquinone backbone (Figure 3).

Acid Blue 62 (AB62) generates an abundant deprotonated molecule upon ionization via negative-ion ESI. CAD experiments showed that deprotonated $\mathrm{AB} 62$ dissociated via loss of alkyl group $\mathrm{C}_{6} \mathrm{H}_{11}$ as the main fragment ion $(\mathrm{m} / \mathrm{z} 316.0155)$ followed by loss of $\mathrm{SO}_{2}$ (yielding an anion with a $\mathrm{m} / \mathrm{z}$ of 289.0060 , Table 2 ). These results suggested that 
Citation: Li M, Chen Y, Hinks D, Vinueza NR (2016) Analysis of Sulfonated Anthraquinone Dyes by Electrospray lonization Quadrupole Time-of-flight Tandem Mass Spectrometry. J Textile Sci Eng 6: 236. doi:10.4172/2165-8064.1000236

the lowest fragmentation energy pathway is the loss of the cyclohexyl group from the deprotonated acid blue as compared to the loss of $\mathrm{SO}_{2}$ (Figure 4). Furthermore, this dissociation pathway is different from the ones observed for acid dyes containing secondary aromatic amines as substituents on the anthraquinone backbone.

Acid Blue 277 forms an abundant deprotonated molecule upon ionization via negative-ion ESI. This ion fragments via loss of $\mathrm{C}_{2} \mathrm{H}_{6} \mathrm{NO}_{3} \mathrm{~S}$ to generate the main fragment ion with a $\mathrm{m} / \mathrm{z} 420.0780$ followed by the loss of $\mathrm{SO}_{2}(\mathrm{~m} / \mathrm{z} 480.1213$, Table 2). This result suggests that the lowest energy path of fragmentation is loss of alkyl groups attached to aromatic ring of the secondary aromatic amine.

The CAD studies of the nine anthraquinone derivatives showed an interesting loss of $\mathrm{SO}_{2}$, which can generate a very stable phenoxide anion useful for quantification by MS/MS. AB25 was selected to test the efficiency of quantitation by this method. The fragment ion with $\mathrm{m} / \mathrm{z}$ 329.0926, generated upon CAD of the deprotonated ion $(\mathrm{m} / \mathrm{z}$ 393.0529), was selected for calibration and sample quantification. The calibration curve is showed in Figure 5.

A solution of $\mathrm{AB} 25$ with a concentration of $50.0 \mu \mathrm{g} / \mathrm{mL}$ was

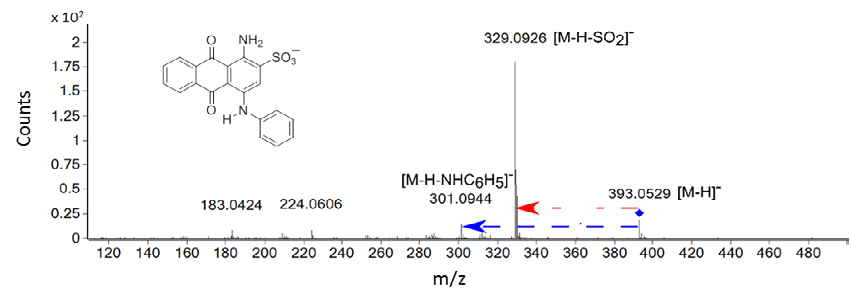

Figure 3: MS/MS spectrum obtained after CAD of the deprotonated molecule of acid blue $25(\mathrm{~m} / \mathrm{z} 393.0529)$

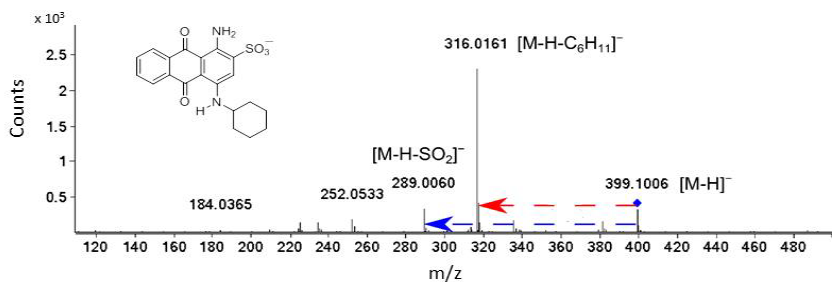

Figure 4: MS/MS spectrum obtained after CAD of the deprotonated molecule of acid blue 62 (m/z 399.1006).

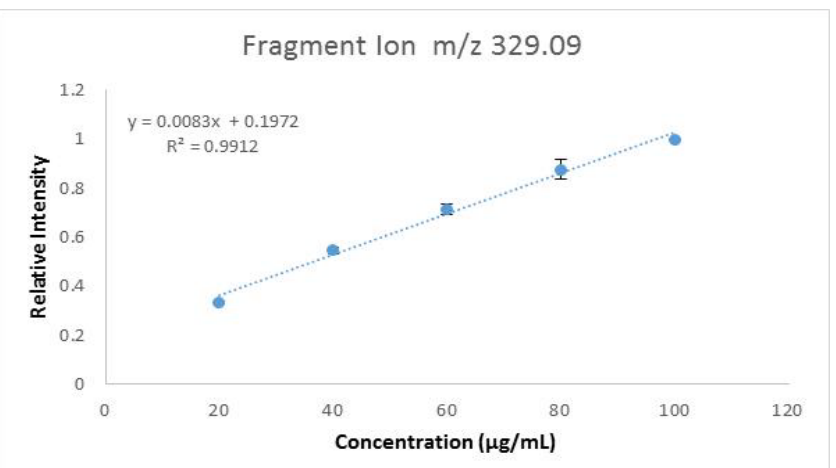

Figure 5: Quantitative analysis of AB $25(20.0 \mu \mathrm{g} / \mathrm{mL}-100.0 \mu \mathrm{g} / \mathrm{mL})$ Bars represent standard deviation analysis for three replicates. The intercept is 0.1972 and slope 0.0083 . quantified by HPLC and by targeted MS/MS. The results of the AB25 solution were for HPLC $50.77 \mu \mathrm{g} / \mathrm{mL}$ and for Targeted MS/MS 54.64 $\mu \mathrm{g} / \mathrm{mL}$. The percent error for the MS/MS method was $7.62 \%$ compared to the HPLC quantification value. The overall results strongly suggest that the phenoxide anion generated by loss of $\mathrm{SO}_{2}$ by $\mathrm{CAD}$ is an exceptional ion for performing MS/MS quantification.

\section{Conclusions}

The deprotonated molecules formed upon negative-ion ESI were subjected to CAD events revealing fragmentation patterns that facilitated the identification of the anthraquinone derivatives. A loss of $\mathrm{SO}_{2}$ was observed for all the sulfonated anthraquinone dyes, which indicated a characteristic rearrangement of $-\mathrm{SO}_{3}$ functional group to form a stable phenoxide fragment ion. It became clear that this was the dominant fragment ion when the dye contained a secondary aromatic amine substituent (e.g., Acid Blue 25). In the presence of alkyl substituent groups on the anthraquinone backbone, the $\mathrm{SO}_{3}$ rearrangement was not the main fragmentation pathway. Quantification by QTOF MS/MS of a sulfonated anthraquinone was feasible when the stable phenoxide anion was selected as observed in the AB25 experiments.

Overall, the fragmentation of acid dyes with similar group functionalities was analyzed. This provided tools for fingerprinting anthraquinone dyes and generating a database of dyes containing sulfonated anthraquinone structures. The results of this study will be applied on the Max Weaver Dye Library for structure characterization.

\section{Acknowledgement}

This work was supported by North Carolina State University startup fund.

\section{References}

1. Edlund PO, Lee ED, Henion JD, Budde WL (1989) The determination of sulfonated azo dyes in municipal wastewater by ion spray liquid chromatography tandem mass spectrometry. Biomed Environ Mass Spectrom 18: 233-240.

2. Fuh M, Chia K (2002) Determination of sulphonated azo dyes in food by ion-pair liquid chromatography with photodiode array and electrospray mass spectrometry detection. Talanta 56: 663-671.

3. Holcapek M, Jandera P, Prikryl J (1999) Analysis of sulphonated dyes and intermediates by electrospray mass spectrometry. Dyes and Pigments 43 127-137.

4. Oliveira DP, Carneiro PA, Sakagami MK, Zanoni MVB, Umbuzeiro GA (2007) Chemical characterization of a dye processing plant effluent-identification of the mutagenic components. Mutation Research/Genetic Toxicology and Environmental Mutagenesis 626: 135-142.

5. Pan H, Feng J, He G, Cerniglia CE, Chen H (2012) Evaluation of impact of exposure of sudan azo dyes and their metabolites on human intestinal bacteria. Anaerobe 18: 445-453.

6. Hunger K (2003) Industrial Dyes: Chemistry, Properties, Applications Weinheim, Germany: Wiley-VCH.

7. Lecchi P, Zhao J, Wiggins WS, Chen T, Yip PF, et al. (2009) A method for monitoring and controlling reproducibility of intensity data in complex electrospray mass spectra: A thermometer ion-based strategy. J Am Soc Mass Spectrom 20: 398-410.

8. Habicht SC, Vinueza NR, Archibold EF, Duan P, Kenttämaa HI (2008) Identification of the carboxylic acid functionality by using electrospray ionization and ion-molecule reactions in a modified linear quadrupole ion trap mass spectrometer. Anal Chem 80: 3416-3421.

9. Prakash C, Shaffer CL, Nedderman A (2007) Analytical strategies for identifying drug metabolites. Mass Spectrom Rev 26: 340-369.

10. Ma SK, Chowdhury SB, Alton K (2006) Application of mass spectrometry for metabolite identification. Curr Drug Metab 7: 503-523.

11. Auld J, Hastie DR (2009) Tandem mass spectrometry and multiple reaction monitoring using an atmospheric pressure chemical ionization triple quadruple 
Citation: Li M, Chen Y, Hinks D, Vinueza NR (2016) Analysis of Sulfonated Anthraquinone Dyes by Electrospray lonization Quadrupole Time-of-flight Tandem Mass Spectrometry. J Textile Sci Eng 6: 236. doi:10.4172/2165-8064.1000236

mass spectrometer for product identification in atmospherically important reactions. International Journal of Mass Spectrometry 282: 91-98

12. Bandu ML, Watkins KR, Bretthauer ML, Moore CA, Desaire H (2004) Prediction of MS/MS data. 1. A focus on pharmaceuticals containing carboxylic acids. Anal Chem 76: 1746-1753.

13. Liu Y, He J, Zhang R, Shi J, Abliz Z (2009) Study of the characteristic fragmentation behavior of hydroquinone glycosides by electrospray ionization tandem mass spectrometry with optimization of collision energy. Journal of Mass Spectrometry 44: 1182-1187.

14. Lopez LL, Tiller PR, Senko MW, Schwartz JC (1999) Automated strategies for obtaining standardized collisionally induced dissociation spectra on a benchtop ion trap mass spectrometer. Rapid Communications in Mass Spectrometry 13 663-668.

15. Habicht SC, Vinueza NR, Amundson LM, Kenttamaa HI (2011) Comparison of functional group selective lon-Molecule reactions of trimethyl borate in different ion trap mass spectrometers. J Am Soc Mass Spectrom 22: 520-530.

16. Amundson LM, Owen BC, Gallardo VA, Habicht SC, Fu M, et al. (2011) Differentiation of regioisomeric aromatic ketocarboxylic acids by positive mode atmospheric pressure chemical ionization collision-activated dissociation tandem mass spectrometry in a linear quadrupole ion trap mass spectrometer. J Am Soc Mass Spectrom 22: 670-682.

17. Amundson LM, Gallardo VA, Vinueza NR, Owen BC, Reece JN, et al. (2012) Identification and counting of oxygen functionalities and alkyl groups of aromatic analytes in mixtures by positive-mode atmospheric pressure chemical ionization tandem mass spectrometry coupled with high-performance liquid chromatography. Energy Fuels 26: 2975-2989.

18. McLuckey SA (1992) Principles of collisional activation in analytical mass spectrometry. J Am Soc Mass Spectrom 3: 599-614.

19. Sleno L, Volmer DA (2004) Ion activation methods for tandem mass spectrometry. Journal of Mass Spectrometry 39: 1091-1112.

20. Mayer PM, Poon C (2009) The mechanisms of collisional activation of ions in mass spectrometry. Mass Spectrom Rev 28: 608-639.
21. Ballantine JA, Games DE, Slater PS (1997) The use of diethylamine to determine the number of sulphonate groups present within polysulphonated alkali metal salts by electrospray mass spectrometry. Rapid Communications in Mass Spectrometry 11: 630-637.

22. Volna K, Holcapek M, Suwanruji P, Freeman HS (2006) Mass spectrometric analysis of sulphonated dyes based on diaminobiphenyls. Coloration Technology 122: 22-26.

23. Rafols C, Barcelo D (1997) Determination of mono-and disulphonated azo dyes by liquid chromatography-atmospheric pressure ionization mass spectrometry. Journal of Chromatography A 777: 177-192.

24. Holcapek M, Jandera $P$, Zderadicka $P$ (2001) High performance liquid chromatography-mass spectrometric analysis of sulphonated dyes and intermediates. Journal of Chromatography A 926: 175-186.

25. Ben-Ari J, Etinger A, Weisz A, Mandelbaum A (2005) Hydrogen-shift isomerism: Mass spectrometry of isomeric benzenesulfonate and 2-, 3-and 4-dehydrobenzenesulfonic acid anions in the gas phase. Journal of Mass Spectrometry 40: 1064-1071

26. Binkley RW, Flechtner TW, Tevesz MJ, Winnik W, Zhong B (1993) Rearrangement of aromatic sulfonate anions in the gas phase. Org Mass Spectrom 28: 769-772

27. Kuki A, Nagy L, Zsuga M, Keki S (2011) Fast identification of phthalic acid esters in poly (vinyl chloride) samples by direct analysis in real time (DART) tandem mass spectrometry. International Journal of Mass Spectrometry 303: 225-228.

28. Kertesz TM, Hall LH, Hill DW, Grant DF (2009) CE 50: Quantifying collision induced dissociation energy for small molecule characterization and identification. J Am Soc Mass Spectrom 20: 1759-1767.

29. Kuki A, Shemirani G, Nagy L, Antal B, Zsuga M, et al. (2013) Estimation of activation energy from the survival yields: Fragmentation study of leucine enkephalin and polyethers by tandem mass spectrometry. J Am Soc Mass Spectrom 24: 1064-1071. 